\title{
Effect of acute administration of sildenafil to rats with detrusor overactivity induced by chronic deficiency of nitric oxide
}

\author{
Ricardo Reges, Carlos D’Ancona, Fabíola Mônica, Edson Antunes \\ Division of Urology (RR, CDA) and Department of Pharmacology (FM, EA), Universidade Estadual de \\ Campinas - UNICAMP, Sao Paulo; Division of Urology, Universidade Federal do Ceara - UFC (RR), \\ Ceara, Brazil
}

\section{ABSTRACT}

Purpose: Recently, the effect of phosphodiesterase inhibitors (PDE5i) in the lower urinary tract symptoms (LUTS) associated to benign prostatic hyperplasia have been studied thoroughly. However, it remains unclear how the PDE5i improve LUTS. Therefore, the aim of the present study was to evaluate the potential of acute administration of the PDE5i sildenafil to improve detrusor overactivity (D0) induced by $\mathrm{N}^{\omega}$-nitro- - -arginine methyl ester hydrochloride (L-NAME), an nitric oxide sinthase (NOS) inhibitor, in rats.

Materials and Methods: Twenty-seven MALE adult Wistar Rats were divided into the following groups: (1) control, (2) L-NAME, (3) sildenafil alone, and (4) L-NAME + sildenafil.

The NOS blocker L-NAME (20 mg/rat/day) was given in the drinking water. Sildenafil $(100 \mu \mathrm{g} / \mathrm{kg})$ was administrated intravenously (i.v.) acutely, diluted in cremophor, propylene glycol and water. All animals underwent to anesthetized cystometograms.

Results: The chronic and systemic administration of L-NAME markedly increased the number of non voiding contractions (2.62 $( \pm 0.89))$, and frequency of micturition (1.97 $( \pm 0.78)$ ), as well increased volume threshold $(2.83 \mathrm{~mL}( \pm 1.64))$ compared with control group, the number of non voiding contractions $(1.17( \pm 0.75))$, frequency of micturition $(1.08( \pm 0.65))$ and volume threshold $(1.16 \mathrm{~mL}( \pm 0.38)), p<0.001, p=0.01$, and $p=0.04$, respectively. Sildenafil infusion decreased the number of micturition cycles significantly from the baseline to end point $(-0.93( \pm 0.34))$ in nitric oxide (NO) deficient animals compared with sildenafil infusion alone (control) in animals with normal NO level $(0.13( \pm 0.25)), p=0.03$. Conclusion: Systemic reduction of nitric oxide causes detrusor overactivity and acute infusion of sildenafil reduces the number of micturition cycles in chronic NO-deficient rats.

\section{ARTICLE INFO}

\section{Key words:}

sildenafil nitrate

[Supplementary Concept];

Nitric Oxide; Lower Urinary

Tract Symptoms

Int Braz J Urol. 2013; 39: 268-75

Submitted for publication:

September 10, 2012

Accepted after revision:

February 20, 2013

\section{INTRODUCTION}

Initially, the rationale for the use of phosphodiesterase inhibitors (PDE5i) in the treatment of lower urinary tract symptoms (LUTS) was based on demographic data showing the frequent occurrence of both erectile dysfunction (ED) and
LUTS in men as they age $(1,2)$. Overall, these preliminary data provide experimental support for the clinical investigation of PDE5i in the treatment of benign prostatic enlargement (BPE)/ LUTS. After the first clinical study reported improvement of LUTS with sildenafil administration for men with DE and BPE in 2002 (2), it has been 
observed a special interest in the role of PDE5i for the treatment of LUTS. Although nowadays there are several studies of high level of evidence supporting the use of PDE5i in LUTS, the mode of action of PDE5i is not yet fully understood.

Sildenafil, an oral PDE5i, is the most commonly prescribed medication for treating ED. By inhibiting the degradation of phosphodiesterase type-5, vascular smooth muscle relaxation is augmented, thus improving corpora cavernosa blood flow. Phosphodiesterase type- 5 has been found throughout the urinary tract, including the corpus cavernosum, clitoris, tunica albuginea, bladder, urethra, prostate, ureter and vagina (3).

The nitric oxide synthase (NOS) inhibitor $\mathrm{N}^{\omega}$-nitro- - -arginine methyl ester hydrochloride (L-NAME) causes significant increase in number of non voiding contractions (NVC) micturition cycles (MC) in rats. The increase in NVC and MC in experimental study has been associated with detrusor overactivity (D0) (4). In addition, the inhibition of arginases, which degrade L-arginine into L-ornithine, decreased neurogenic DO in chronic spinal cord-injured (SCI) rats (5). Recently, it was also showed that 4-week treatment with the NOS blocker L-NAME causes in vitro detrusor smooth muscle (DSM) supersensitivity to muscarinic agonists via increased levels of $\left[\mathrm{H}^{3}\right]$-inositol-phophate, accompanied by reductions of $\beta_{3}$-adrenoreceptor mediated DSM relaxations (6).

Therefore, the aim of the present study was to evaluate the potential of acute administration of sildenafil to improve DO induced by an NOS inhibitor L-NAME in rats.

\section{MATERIALS AND METHODS}

\section{Animals}

The experimental protocols were approved by the Ethical Principles in Animal Research adopted by the Brazilian College for Animal Experimentation. Male Wistar rats (220-310 g) were used.

\section{Experimental Groups}

Animals were randomized into four experimental groups, as follows:
G1: rats $(n=6)$ : control group: the rats received drinking water ad libitum

G2: rats $(\mathrm{n}=6)$ : received L-NAME (20mg/ rat/day) in drinking water for 4 weeks

G3: rats $(n=4)$ : received sildenafil $(100 \mu \mathrm{g} /$ $\mathrm{Kg})$ (i.v.) in a single injection.

G4: rats $(\mathrm{n}=6)$ : received L-NAME $(20 \mathrm{mg} /$ rat/day) in drinking water for 4 weeks + sildenafil $(100 \mu \mathrm{g} / \mathrm{Kg})($ i.v. $)$ in a single injection.

The volume of water drunk by each rat was approximately $50 \mathrm{~mL} / \mathrm{rat} /$ day. Doses of L-NAME and sildenafil were chosen according to our previous studies (7).

\section{Cystometry in Anesthetized Rats}

Rats were anesthetized with an intraperitoneal injection of urethane $(1.2 \mathrm{~g} / \mathrm{kg})$, and the carotid artery cannulated for mean arterial blood pressure (MABP) monitoring. A 1-cm incision was made along the midline of the rat abdomen. The bladder was exposed and a butterfly needle (19G) was inserted into the bladder dome and connected to a pressure transducer and to an infusion pump. Before starting the cystometry, the bladder was emptied. Continuous cystometry (CMGs) was carried out by infusing saline into the rat bladder at a rate of $4 \mathrm{~mL} / \mathrm{hr}$. The following parameters were assessed: number of non-voiding contraction (NVCs), threshold pressure (TP) $\mathrm{mmHg}$ - at which micturition began, the peak pressure (PP) $\mathrm{mmHg}$ - during micturition, volume threshold (VT) mL that was calculated by the time needed for the first micturition X $4 \mathrm{~mL} / 60$ min., micturition cycle (MC) calculated as number of cycles per minute and basal vesical pressure (BP). NVCs were considered as spontaneous bladder contractions $>4 \mathrm{mmHg}$ from the baseline pressure that did not result in a void. The urodynamic variables evaluated and the methodology used in the cystometry match those described in the literature (8).

\section{Statistics}

Data are expressed as mean \pm SD of $n$ experiments. Statistical significance of the differences was studied by analysis of variance (ANOVA) and posteriorly by Bonferroni method. $\mathrm{P}<0.05$ was accepted as significant. The software Gra- 
phPad Prism ${ }^{\circledR}$ version 5.00 for Windows ${ }^{\circledR}$ (GraphPad Software, San Diego, California, USA, 2007) was used for the statistical analysis.

\section{Drugs}

$\mathrm{N}^{\omega}$-nitro-L-arginine methyl ester hydrochloride and urethane were obtained from Sigma Chem. Co. (St Louis, MO) and Sildenafil from Biolab (SP, Brazil).

\section{RESULTS}

The chronic and systemic administration of L-NAME (G2) resulted in a significant increase in total number of non voiding contractions (2.62 ( \pm 0.89$))$ compared with control (G1) (1.17 ( \pm $0.75))(\mathrm{p}<0.001$; Figure-1). Volume threshold was also significantly increased in L-NAME-treated rats (G2) $(2.83 \mathrm{~mL}( \pm 1.64))$ when compared with control (G1) (1.16 mL $( \pm 0.38))(p=0.01$; Figure-2). No significant difference was observed in the threshold pressure, peak pressure and basal bladder pressure comparing L-NAME group with control (Table-1).
The number per minute of micturition cycles significantly increased in L-NAME-treated groups (G2 and G4) when compared with control (G1) or sildenafil groups (G3) $(\mathrm{P}=0.04$; Figure-3). Sildenafil infusion to chronically L-NAME treated rats (G4) decreased the number of MC significantly from the baseline to end point $(-0.93( \pm 0.34))$ compared with sildenafil infusion alone (G3) (0.13 $( \pm 0.25)), p=0.03$ (Figure-4; Table-2).

The mean time for the response after sildenafil infusion was $21.58( \pm 13.18)$ minutes.

L-NAME (G1) administration increased significantly the systemic blood pressure (BP) (200.3 $( \pm$ 6.77)) $\mathrm{mmHg}$ compared with control (G2) (116.9 $( \pm 3.35) \mathrm{mmHg})(\mathrm{p}<0.05)$. Comparing the baseline BP (before sildenafil) with endpoint BP (after sildenafil infusion) in the G4 group, it was not observed significant change in the arterial blood pressure (Figure-5).

\section{DISCUSSION}

In the present study, a chronic deficiency of NO was induced by L-NAME. The animals un-

Figure 1 - Number of non-void contractions (NVC) in N0-deficient animals (G2 and G4) compared with controls (G1 and G3). Analysis of variance $($ ANOVA) between groups $(\mathrm{p}<0.001)$. G1 = Control, G2 = L-NAME, G3 = Sildenafil alone, and (G4 = L-NAME + Sildenafil.

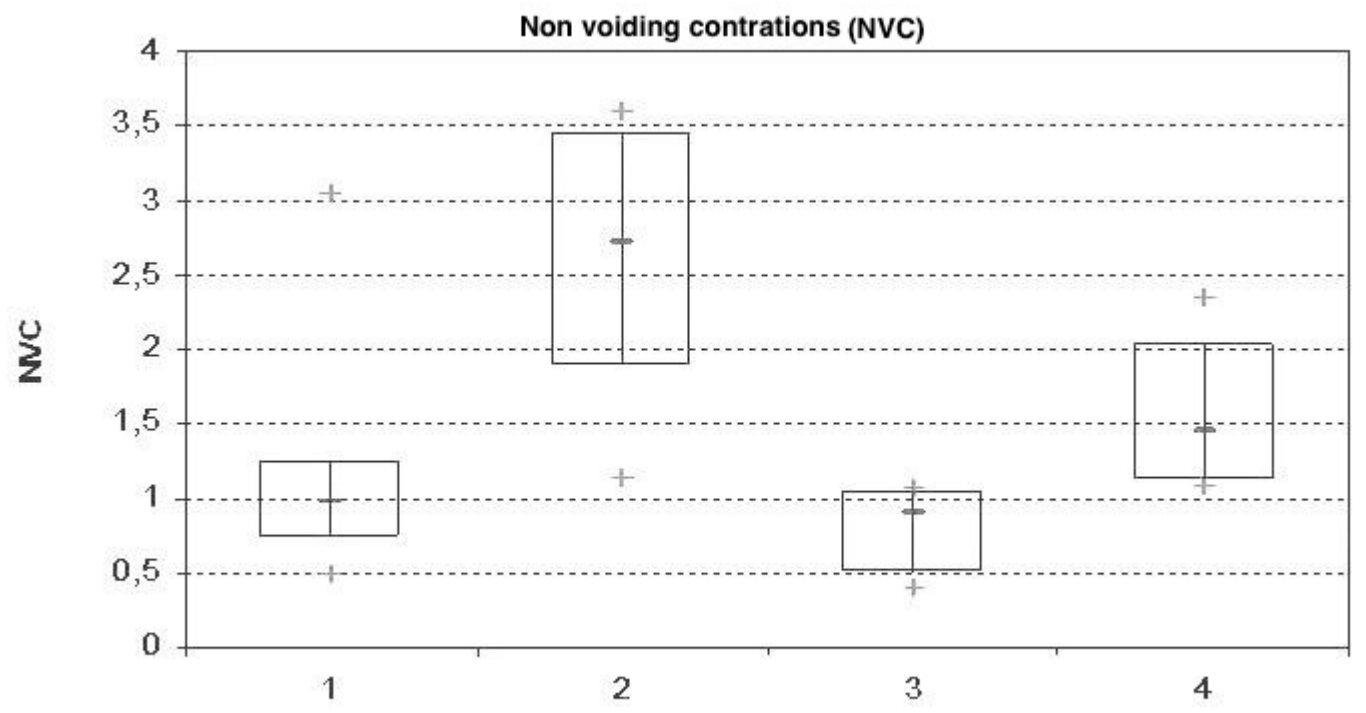


Figure 2 - Increase in volume threshold (VT) in NO-deficient animals (G2 and G4) compared with controls (G1 and G3). Analysis of variance $(A N O V A)$ between groups $(p=0.01)$. G1 = Control, G2 = L-NAME, G3 = Sildenafil alone, and $(G 4=L-N A M E+$ Sildenafil.

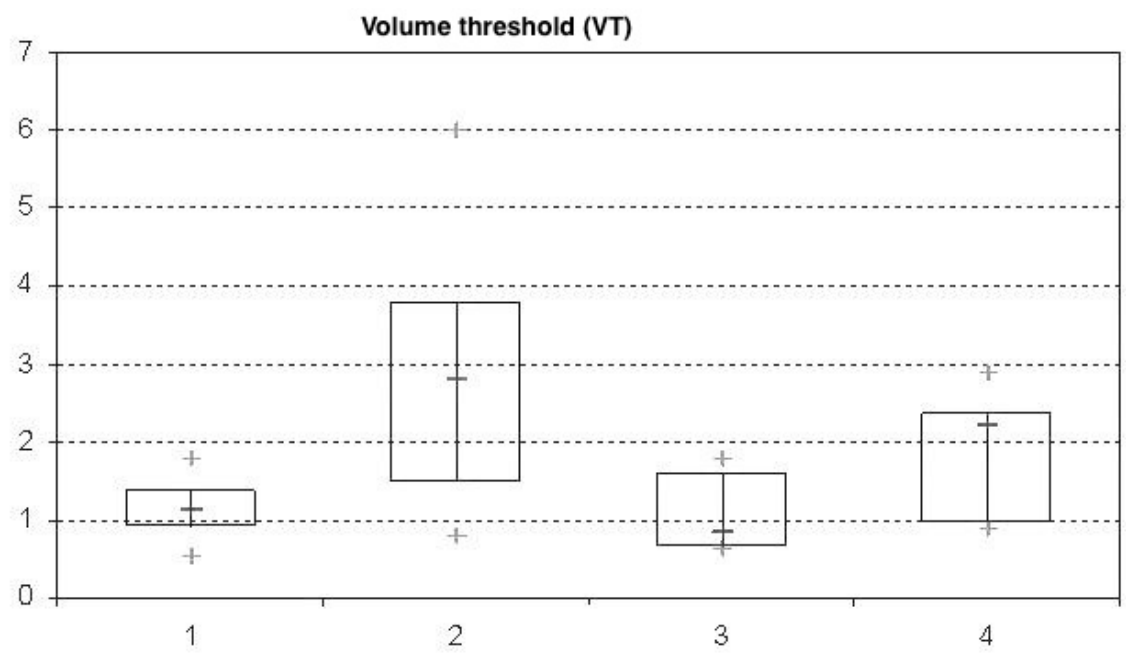

Group

Table 1 - Administration of $\mathbf{N}^{\omega}$-nitro-L-arginine methyl ester hydrochloride (L-NAME) to G1 and G4 rats resulted in increased number of non voiding contractions, volume threshold, and micturition cycles compared to the animals with normal level of nitric oxide at end point and before sildenafil infusion (G2 and G3, respectively).

\begin{tabular}{lcccc}
\hline Variables & $\begin{array}{c}\text { Group } 1 \\
(\mathrm{n}=6) \\
\text { Mean } / \pm \mathrm{SD}\end{array}$ & $\begin{array}{c}\text { Group } 2 \\
(\mathrm{n}=6) \\
\text { Mean } / \pm \mathrm{SD}\end{array}$ & $\begin{array}{c}\text { Group } 3 \\
(\mathrm{n}=4) \\
\text { Mean } / \pm \mathrm{SD}\end{array}$ & $\begin{array}{c}\text { Group } 4 \\
(\mathrm{n}=6) \\
\text { Mean } / \pm \mathrm{SD}\end{array}$ \\
\hline NVC & $1.17 / \pm 0.75$ & $2.62 / \pm 0.89^{\dagger}$ & $0.82 / \pm 0.30$ & $1.56 / \pm 0.74^{\ddagger}$ \\
VT & $1.16 / \pm 0.38$ & $2.83 / \pm 1.64^{\dagger}$ & $1.03 / \pm 0.54$ & $1.09 / \pm 0.78^{\ddagger}$ \\
PT & $19.14 / \pm 3.02$ & $19.13 / \pm 2.90$ & $21.63 / \pm 4.50$ & $28.16 / \pm 11.39$ \\
PP & $21.14 / \pm 3.06$ & $20.05 / \pm 2.93$ & $23.15 / \pm 4.77$ & $30.33 / \pm 11.12$ \\
MC & $1.08 / \pm 0.65$ & $1.97 / \pm 0.78^{\dagger}$ & $1.27 / \pm 0.37$ & $1.38 / \pm 0.17^{\ddagger}$ \\
BP & $11.69 / \pm 6.77$ & $13.73 / \pm 3.35$ & $16.50 / \pm 3.11$ & $21.00 / \pm 14.08$ \\
\hline
\end{tabular}

G1 = Control, G2 = L-NAME, G3 = Sildenafil alone, and G4 = L-NAME + Sildenafil

NVC - non-voiding contraction, TP - threshold pressure, PP - peak pressure, VT - volume threshold, MC - micturition cycled and BP - basal pressure. SD - standard deviation, ANOVA - analysis of variance.

The symbols $\dagger(P<0.05)$ and $\ddagger(P<0.05)$ denote statistically significant differences in relation to G1 and G3, respectively (Tukey's multiple comparison test). 
Figure 3 - Increase in number of micturition cycle (MC) in NO-deficient animals (G2 and G4) compared with controls (G1 and G3). Analysis of variance (ANOVA) between groups $(p<0.05)$. G1 = Control, G2 = L-NAME, G3 = Sildenafil alone, and (G4 = L-NAME + Sildenafil.

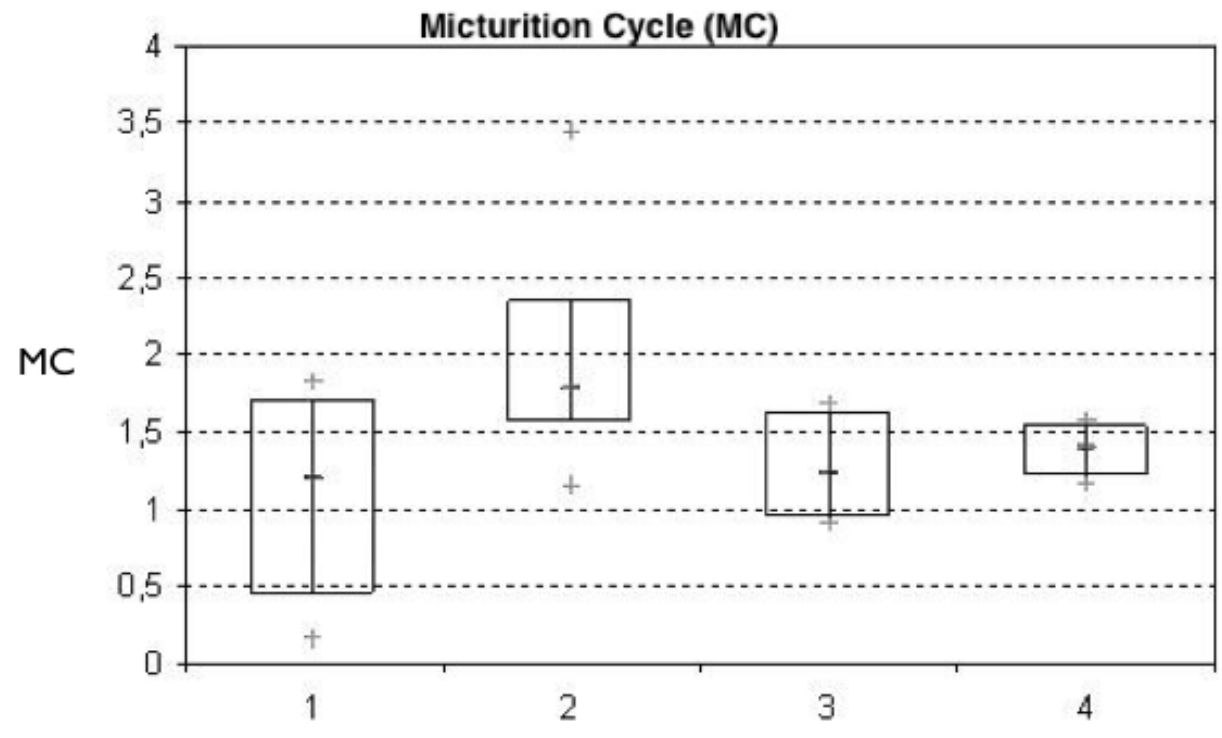

Group

Figure 4 - Representative traces showing no change in the amplitude ( $\mathrm{mmHg}$ ) and number of micturition cycles (MC) after sildenafil infusion in a animal of G3 (A), and decrease in amplitude and number of MC after sildenafil infusion in a rat of G4 (B). The $y$-axis scale was stadardized to $5 \mathrm{mmHg}$ and the $\mathrm{x}$-axis for intervals of 4 minutes.
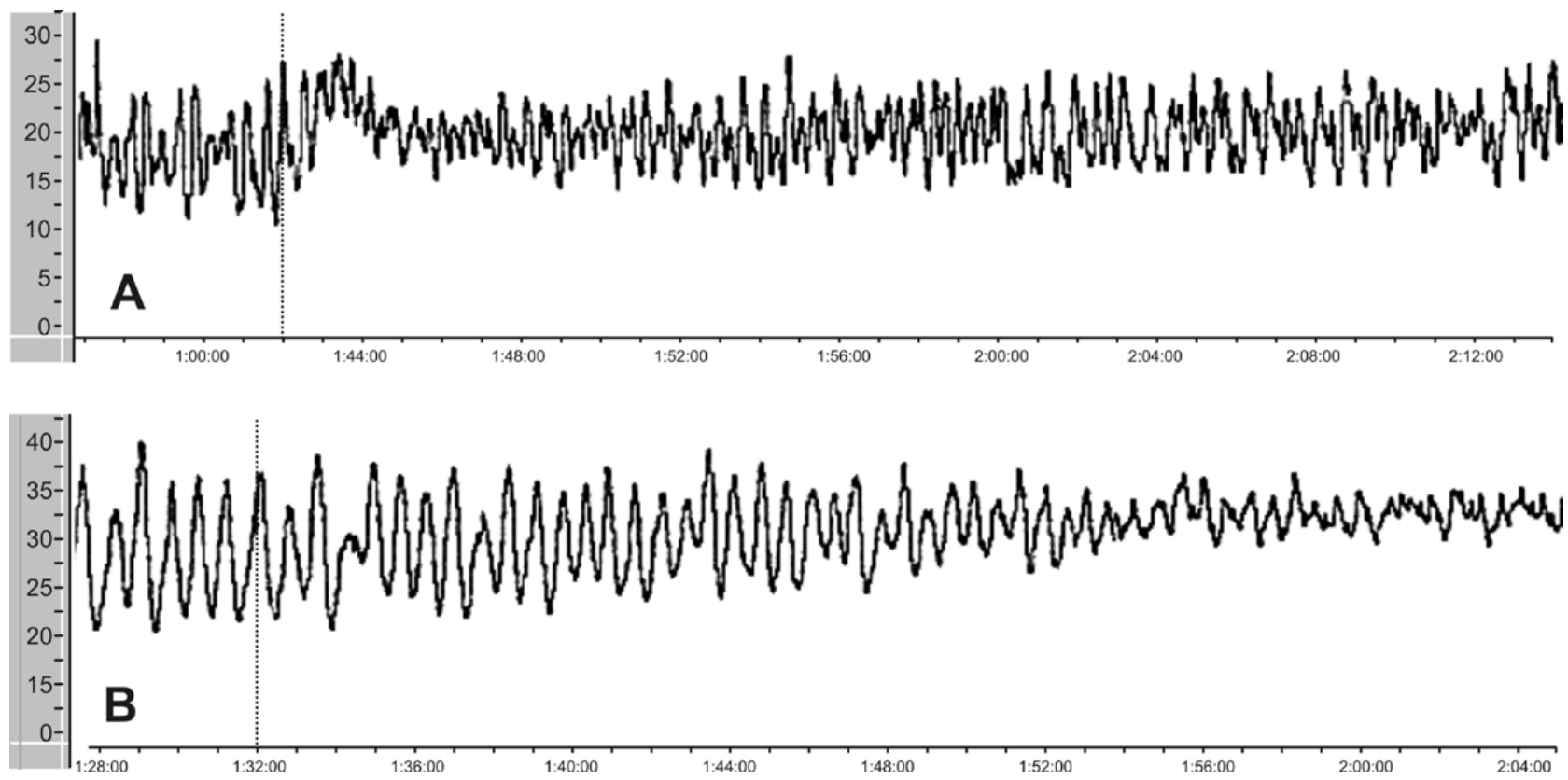

G3 = Single sildenafil injection

G4 = Chronic administration of L-NAME + single sindenafil injection 
Table 2 - Change of number and amplitude of micturition cycles from baseline (before sildenafil) to end point (after sildenafil).

\begin{tabular}{lccccccccc}
\hline & \multicolumn{2}{c}{ G3 } & \multicolumn{7}{c}{ G4 } \\
\hline Variable & N & Mean & SD & $P$ & Variable & N & Mean & SD & $P$ \\
\hline DIF MC (mmHg) & 4 & 0.13 & 0.25 & 0.875 & DIF MC (mmHg) & 6 & -0.93 & 0.34 & 0.031 \\
DIF AMPLIT (mmHg) & 4 & -0.50 & 1.71 & 0.999 & $\begin{array}{c}\text { DIF AMPLIT } \\
(\mathrm{mmHg})\end{array}$ & 6 & -17.50 & 11.72 & 0.031 \\
\hline
\end{tabular}

G3 = sildenafil and $\mathbf{G 4}=\mathrm{L}-\mathrm{NAME}+$ sildenafil

DIF MC = Difference (Delta) of micturition cycles

DIF AMPLIT = Difference (Delta) of amplitude

SD = Standard Deviation

$\mathbf{P}$ refer to comparison from baseline to end point for each group

Figure 5 - Representative traces showing no significative change in the BP $(\mathrm{mmHg})$ after sildenafil in a NO-deficient animal (G4). It was also observed decrease in amplitude and number of MC after sildenafil infusion in the same animal.

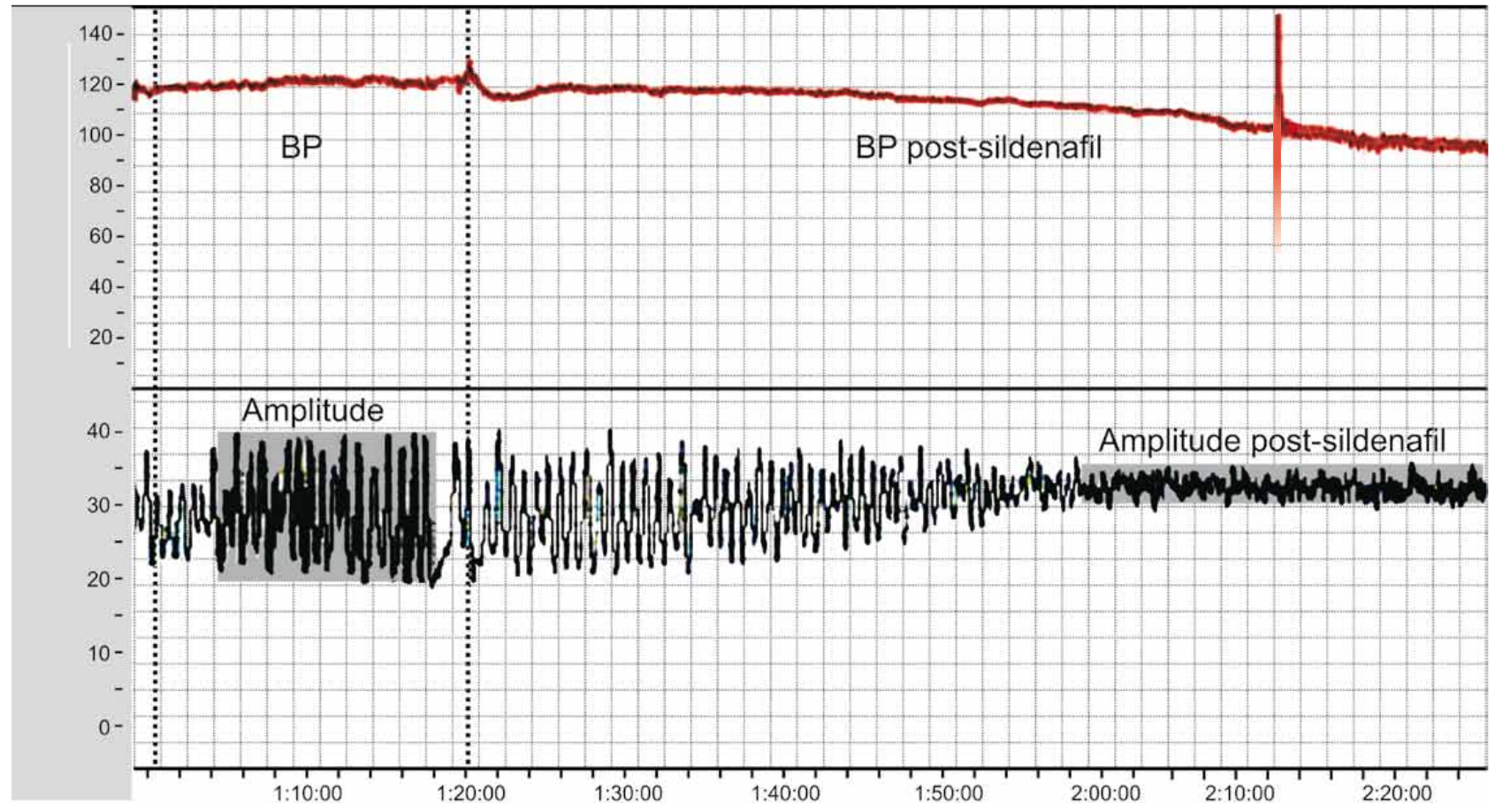

BP = Blood pressure

derwent CMG and it was observed significant increase in NVC and VT in rats.

Therefore, a higher volume threshold becomes necessary to initiate micturition. There are two theories that could explain this observation: increased urethral resistance or detrusor impair- ment. However, as micturition of the L-NAME rats had detrusor pressure similar to control, it suggests an increased urethral resistance. This hypothesis is corroborated by in vitro pharmacological studies, which report that nitric oxide provides relaxation of the urethral smooth muscles $(9,10)$. These results 
suggest that NO has an inhibitory effect in muscular relaxation both in the bladder and in the urethra of animals with chronic deficiency of NO. As demonstrated in a previous experimental study, the systemic reduction of NO causes detrusor overactivity with a decrease in the functional relaxation of the urethra $(4,6)$.

Chronic L-NAME treatment also increased the number of micturition cycles in comparison with control animals. In this study, acute administration of sildenafil during the voiding phase decreased amplitude and number of micturition cycles in the rats with chronic deficiency of NO; however, it did not alter these variables in the control group (G3), with normal NO level.

The exact mechanism through which phosphodiesterase inhibitors alleviate BPE/LUTS remains unclear (11). Also, the pathophysiological relationship between ED and LUTS is not clear yet, but there are several theories to explain it. The candidate mechanisms include pelvic atherosclerosis, autonomic hyperactivity, the calcium-independent Rho-kinase activation pathway and reduced NO levels. It is likely that there is an overlap between the roles of each of these candidate mechanisms, and an ultimate effect leading to smooth muscle relaxation in prostatic, bladder neck, or erectile tissues appears to be crucial. Probably the hypothesis of the reduction of NO is the best explanation.

Increased smooth muscle tension plays a central role in LUTS pathophysiology. The NO/cyclic guanosine monophosphate (cGMP) pathway is one of the major regulators of smooth muscle contractility. Nitric oxide can activate guanylate cyclase, the enzyme that produces cGMP. The accumulation of intracellular cGMP triggers a cascade, leading to decreased intracellular calcium level and subsequent relaxation of smooth muscle cells (SMCs). And the amount of cGMP results from the balance between production (NO) and degradation made by phosphodiesterase are enzymes that can hydrolyze and inactivate cyclic nucleotides. It is known that NO is involved in relaxation of the detrusor, bladder neck, urethra and prostate $(6,12)$.

Clinical trials consistently demonstrated that PDE5i significantly improve IPSS, most studies failed to observe significant improvement in uroflowmetry parameters (13-15). A randomized, double- -blind and placebo controlled clinical trial showed that tadalafil, a phosphodiesterase type 5 inhibitor, when administrated in association with tamsulosin improves significantly more the storage symptoms compared with isolated use of alfa-blocker (16). In consequence, the reduction demonstrated in the number per minute of micturition cycles after acute infusion of sildenafil in NO-deficient rats reinforces the hypothesis that PDE5 inhibitors may exert their effects probably via bladder.

This study has some limitations. It has been previously known that L-NAME is a non specific NOS inhibitor that when administered systemically could affect various levels of neuronal or endothelia. In consequence, it has the potential to alter physiology of lower urinary tract throughout these mechanisms. Additionally, we did not evaluate the pharmacological effects on molecular or morphological grounds of lower urinary tract.

\section{CONCLUSIONS}

Systemic reduction of nitric oxide causes detrusor overactivity and acute infusion of sildenafil reduces the number of micturition cycles in chronic NO-deficient rats.

\section{CONFLICT OF INTEREST}

None declared.

\section{REFERENCES}

1. Braun M, Wassmer G, Klotz T, Reifenrath B, Mathers M, Engelmann U: Epidemiology of erectile dysfunction: results of the 'Cologne Male Survey'. Int J Impot Res. 2000; 12: 305-11.

2. Blanker MH, Bohnen AM, Groeneveld FP, Bernsen RM, Prins A, Thomas S, et al.: Correlates for erectile and ejaculatory dysfunction in older Dutch men: a community-based study. J Am Geriatr Soc. 2001; 49: 436-42.

3. Uckert S, Hedlund P, Andersson KE, Truss MC, Jonas U, Stief CG: Update on phosphodiesterase (PDE) isoenzymes as pharmacologic targets in urology: present and future. Eur Urol. 2006; 50: 1194-207; discussion 1207.

4. Mónica FZ, Reges R, Cohen D, Silva FH, De Nucci G, D’Ancona CA, et al.: Long-term administration of BAY 41-2272 prevents bladder dysfunction in nitric oxide-deficient rats. Neurourol Urodyn. 2011; 30: 456-60. 
5. Sasatomi K, Hiragata S, Miyazato M, Chancellor MB, Morris SM Jr, Yoshimura N: Nitric oxide-mediated suppression of detrusor overactivity by arginase inhibitor in rats with chronic spinal cord injury. Urology. 2008; 72: 696-700.

6. Mónica FZ, Bricola AA, Báu FR, Freitas LL, Teixeira SA, Muscará MN, et al.: Long-term nitric oxide deficiency causes muscarinic supersensitivity and reduces beta(3)-adrenoceptormediated relaxation, causing rat detrusor overactivity. $\mathrm{Br} \mathrm{J}$ Pharmacol. 2008; 153: 1659-68.

7. Ribeiro MO, Antunes E, de Nucci G, Lovisolo SM, Zatz R: Chronic inhibition of nitric oxide synthesis. A new model of arterial hypertension. Hypertension. 1992; 20: 298-303.

8. Tsukimi Y, Mizuyachi K, Matsumoto H, Sato M, Ng B, Tajimi M: Mechanism of action by which aspirin alleviates detrusor hyperactivity in rats. J Pharmacol Sci. 2004; 95: 101-7.

9. Parlani M, Conte B, Manzini S: Nonadrenergic, noncholinergic inhibitory control of the rat external urethral sphincter: involvement of nitric oxide. J Pharmacol Exp Ther. 1993; 265: 713-9.

10. Andersson KE, Garcia Pascual A, Forman A, Tottrup A: Nonadrenergic, non-cholinergic nerve-mediated relaxation of rabbit urethra is caused by nitric oxide. Acta Physiol Scand. 1991; 141: 133-4.

11. Dmochowski R, Roehrborn C, Klise S, Xu L, Kaminetsky J, Kraus $\mathrm{S}$ : Urodynamic effects of once daily tadalafil in men with lower urinary tract symptoms secondary to clinical benign prostatic hyperplasia: a randomized, placebo controlled 12-week clinical trial. J Urol. 2010; 183: 1092-7.
12. Uckert S, Sormes M, Kedia G, Scheller F, Knapp WH, Jonas $U$, et al.: Effects of phosphodiesterase inhibitors on tension induced by norepinephrine and accumulation of cyclic nucleotides in isolated human prostatic tissue. Urology. 2008; 71: 526-30.

13. McVary KT, Monnig W, Camps JL Jr, Young JM, Tseng LJ, van den Ende G: Sildenafil citrate improves erectile function and urinary symptoms in men with erectile dysfunction and lower urinary tract symptoms associated with benign prostatic hyperplasia: a randomized, double-blind trial. J Urol. 2007; 177: 1071-7.

14. McVary KT, Roehrborn CG, Kaminetsky JC, Auerbach SM, Wachs B, Young JM, et al.: Tadalafil relieves lower urinary tract symptoms secondary to benign prostatic hyperplasia. $J$ Urol. 2007; 177: 1401-7.

15. Stief CG, Porst H, Neuser D, Beneke M, Ulbrich E: A randomised, placebo-controlled study to assess the efficacy of twice-daily vardenafil in the treatment of lower urinary tract symptoms secondary to benign prostatic hyperplasia. Eur Urol. 2008; 53: 1236-44.

16. Regadas RP, Reges R, Cerqueira JB, Sucupira DG, Josino IR, Nogueira $E$, et al.: Urodynamic effects of the combination of tamsulosin and daily tadalafil in men with lower urinary tract symptoms secondary to benign prostatic hyperplasia: a randomized, placebo-controlled clinical trial. Int Urol Nephrol. 2013; 45: 39-43.

\footnotetext{
Correspondence address:

Dr. Ricardo Reges M. Oliveira Rua Antonele Bezerra 280

Fortaleza, Ceara, 60160-070, Brazil Fax: + 5585 3262-3730
}

E-mail: consultoriodeurologia@gmail.com 